\title{
Research on Important Functions and Applications Models of Mathematics History in College Mathematics Teaching
}

\author{
Gaiyan Bai ${ }^{1,2}$ \\ ${ }^{1}$ Center for the History of Mathematics and Sciences, Northwestern University, Xi'an, 710127, China \\ ${ }^{2}$ Department of Mathematics, Shaanxi Preschool Normal University, Xi’an, 710061, China
}

Keywords: Mathematics history, Higher mathematics, College mathematics teaching

\begin{abstract}
The integration of mathematics history and college mathematics teaching can help to stimulate student's interest, strengthen knowledge understanding and enhance humanistic quality. The paper explores the important functions of mathematics history in college mathematics teaching and analyzes the models of the application of mathematics history in college mathematics teaching to provide some references for the relative researchers.
\end{abstract}

\section{Introduction}

College mathematics is an important foundation and tool course, extensive application and fundamental disciplines not only make mathematics foundation and tool for studying other courses, but also make mathematics carrier of improving students' comprehensive quality excellent. The history of mathematics is the study of mathematical concepts, mathematical methods, and the origin and development of mathematical ideas, and its connection with social, economic and cultural life. The history of mathematics flexibly penetrated college mathematics teaching occupation colleges, not only can effectively stimulate students' interest in learning mathematics and improve the enthusiasm of learning mathematics, and plays an important role in improving the understanding of mathematics and logical thinking ability. College mathematics is a basic discipline made up of college mathematics, linear algebra, probability theory and mathematical statistics. It lays a solid theoretical foundation for the further study of students and the thorough exploration of specialized courses. There is no doubt about the importance of university mathematics in the whole university course, but it often falls into a dilemma during teaching. Teachers use immutable classical textbooks, but they are often seriously out of line with the practical application of specialized courses. Teaching methods have always been mainly indoctrination, lack of problem oriented teaching practice and so on. In fact, there are many ways to get out of the predicament, which are worthy of further study and discussion by the mathematics educators. The object of this thesis is one of them: the application of history of mathematics in College Mathematics teaching. The teacher will be the history of mathematics into the daily teaching process, concept, theorem and method of using the derivative process of historical development and mathematics to help students master the university mathematics, lead the students to realize the wide application of mathematics.

\section{Important Functions of Mathematics History in College Mathematics Teaching}

Stimulate Student's Interest. The teacher integrates the history of mathematics in the teaching of higher mathematics, can not only enrich the learning content, arouse students' learning enthusiasm, also can make the students' thinking ability and innovation consciousness and improve training. Through the introduction of mathematical concepts, formulas and the development of the historical background and social background, the content of mathematics learning can enable students to understand the sequence of events and have a perceptual knowledge of the emergence and 
development of knowledge, but also to understand the future trend of the development of knowledge. In addition, the teacher can also introduce some famous mathematicians to the students during teaching and encourage them to study advanced mathematics seriously. Application of mathematics history in the university mathematics teaching, classroom teaching interaction, can maximize the weakening of students in learning difficulties, the original boring and abstract mathematical definitions, into simple vivid examples, which has a certain guiding significance, but also more convenient for students to understand. In the teaching of simple introduction of the relevant history of mathematics, can make students proud of our country's splendid civilization, but also can stimulate students for the rise of China and study hard patriotic enthusiasm. Therefore, in the university mathematics teaching, mathematics related to historical events, which can greatly stimulate students to learn mathematics in University historical mission, the infinite power and can enhance the learning of mathematics. In the teaching activities of college mathematics, the timely introduction of some similar examples will make the class lively and interesting, and more importantly, it will help the formation of students' good and subtle good character. Acceptance from the perspective of the history of mathematics students, promote students' psychological acceptance, help students form the self-cognition of the mathematics concept to promote students to thoroughly grasp knowledge and stimulate the students' interest.

Strengthen Knowledge Understanding. The students' understanding of higher mathematics is only the basic concept and formula of the abstract, but do not understand the nature of these concepts and formulas. This kind of teaching mode of higher mathematics not only make students lose interest in learning, tired, but more difficult to achieve higher mathematics teaching goal. The history of mathematics into higher mathematics teaching, can not only make the mathematical knowledge become fresh, enable students to actively learn advanced mathematics, can make the level of mathematics students cultural quality improved thus, the higher mathematics teaching goal. In the practical sense of mathematics history, there are many stories about teaching mathematicians in creative thinking and developing new theories, which, in many ways, have enlightening implications for contemporary college students. There are more systems that can be studied by using various assumptions about the reduction or cancellation of ordinary algebra, or by assuming one or more of the assumed ones. In this instance, let the student from a more fundamental point of view to study their algebraic thinking to understand, for the knowledge of the sequence of events also have a certain understanding, in the process, students are more prone to the ideas and methods of new problems.

Enhance Humanistic Quality. The conjectures and proofs of many mathematical problems have been innumerable failures by mathematicians, and even by lifelong effort. For example, Fermat's theorem proposed by French mathematician Fermat is mathematicians around the world after several hundred years of persistent efforts to prove. During this period, although some mathematicians devoted all their life to the proof and failed to prove the conclusion, there were many unexpected findings in the process of proof. Progress in algebraic number theory and algebraic geometry in some milepost type are closely linked to Fermat's theorem. Fermat's theorem is referred to as many golden eggs. The students should not only learn the mathematicians study spirit, but also to learn not only to result in solving problems, we should pay more attention to the process, learn to always find problems, solve problems, so that the students can get a lot of fun from learning and research. The history of mathematics also provides material for improving dialectical materialism and historical materialism. It is also a vivid textbook to illustrate the brilliant achievements of the motherland's mathematics, to raise national pride and to foster patriotism. Mathematics, especially advanced mathematics, contains abundant dialectical materialism. The development of mathematics is determined by the development of productive forces and the progress of society, and it is also the result of the movement of internal contradictions in mathematics. Mathematics is the science of the spatial form and quantity relation of the real world. It is a scientific language and an effective tool to depict the laws of nature and social laws. Mathematics is an objective dynamic reflection of the real world, but this kind of reflection is a dialectical unity of abstract and concrete, subjective and objective. Foreign language majors may be more aware of the brevity of language in their major studies, while students in art majors may realize the beauty of art in their professional studies. In aesthetics, mathematics and many subjects have the 
same beauty as well as the beauty of individuality. Mathematics is full of concise beauty, strange beauty, symmetrical beauty and abstract beauty.

\section{Applications Models of Mathematics History in College Mathematics Teaching}

Launch Courses of Mathematics History. Universities should set up a course in history of mathematics. In support of this, a group of teachers with a history of mathematics should also be required. Because most teachers will face primary and secondary school students. As a teacher of primary and middle school students, there is no basic knowledge of mathematics history and cannot teach students well. More importantly, we should not underestimate the educational value of the history of mathematics. Furthermore, as a teacher, not only the knowledge, only to understand mathematical knowledge of the occurrence and development of the historical process, the rich connotation of discovery and understanding of mathematics content to impart knowledge and skills at the same time, a profound analysis of mathematics as human cultural activities is increasing students' knowledge level. The teacher taught in the class to penetrate the history of mathematics, so that students not only to understand the mathematical concept of individual and is associated with this conceptual background, is conducive to the students to understand the concept, but also broaden the horizons of students. At the same time, for students in engineering colleges, they have a certain knowledge of mathematical history, which can broaden their horizons and enrich their knowledge base. The methodology of mathematics is an organic part of the history of mathematics, and the exploration of methodology is of great significance to the teaching of College mathematics. The students with questions of lectures, and further promote the students' interest in teaching content, promote the students' understanding in spontaneously formed understanding limit, and gradually enjoy their sympathy with the ancient mathematician.

Impart Knowledge of Mathematics History. Integrating the history of mathematics in higher mathematics teaching and curriculum contents are closely linked, it can make students understand the emergence, development and improve the process before learning the content of mathematics, and help the student to master the methods of mathematical ideas and hidden. In the choice of the history of mathematics content, teachers cannot simply repeat the history. The need for two processing on it, which can help the students to find the main elements, and the history of mathematics content naturally into the teaching process, to stimulate students' learning enthusiasm. A part of the history of mathematics is mathematics. To explain the history of mathematics is to compare the same mathematical concept in the ancient and modern times, and find out the similarities and differences between the two, to show the process of the development of mathematics, and to inspire students to learn the ideas of mathematics. For example, the concept of function is a basic mathematical concept have different definitions in different subjects in middle school and University, to clarify the situation, to understand the change process of function from the angle of history, meaning that the students understand the function of the. Ancient and modern mathematical concepts in the expression will be greater differences, in ways are not the same. In the teaching, we should go deep into the scene at that time, and understand the background of the mathematical theorem or formula, the symbols used and the methods adopted. As for the development of modern mathematics, to show the achievements of the new discipline of students, you need to use the metaphor of the image, vivid examples will frontier mathematicians work express, so that students can understand modern mathematics, has been the pursuit of professional, lofty aspirations and goals. Although the history of mathematics into higher mathematics teaching is significant, but it is not the subject. Because the content of higher mathematics but much less, so the introduction of the history of mathematics content, time should not be too long, can not deviate from the focus of teaching at great length about the history of mathematics, to short the main point, or cause students to think. Or make the students relaxed moment in proper adjustment, not overwhelming.

Recommend Books of Mathematics History. Mathematics as a common language of science, more and more widespread attention. With all relevant mathematical history books emerged. Some of these books is in chronological order written, some mainstream discipline as a clue to write, some in 
chronological order and discipline development of the combination of written clues most of these materials, and so on. We can provide rich content and achievements of the research on the history of mathematics in China and abroad. Our question is how to put these rich contents rationally into a form of education, suitable for the tastes of the students, make students read of intense interest. In the teaching of mathematical history, we should focus on expanding the field of vision, enhancing the quality, and cultivating the sentiment. The content of elementary mathematics should be larger, especially the study of the history of mathematical topics. This can lay a good foundation for students to engage in secondary mathematics teaching in the future. After all, teacher's college is to train teachers as its mission, teaching and educating people as the foundation. For college students, do not have systematic knowledge of the deliberate pursuit of the history of mathematics teaching, profound thoughts, and let them learn and imitate the history of great mathematicians put forward questions, concrete thinking method and way to solve the problem, to inspire them to learn that. The author with profound skill and knowledge, the boring math problems easy and interesting to show in front of the reader, as the popularization of mathematics reading works, not only can make the students understand the history of many famous mathematical problems, but also can understand and recognize the latest developments in mathematics, to stimulate interest in mathematics and advocating the spirit of science.

\section{Conclusion}

The history of mathematics and mathematics education influence each other and infiltrate each other to form an organic whole. The combination of the history of mathematics and the teaching of college mathematics has become a hot topic of mathematics education in the world. College mathematics teachers should try their best to explore and excavate the educational function of mathematics history in college mathematics education, study the application models of mathematics history in college mathematics teaching to promote the improvement of teaching quality.

\section{Acknowledgements}

The research is the result of "Subject of 12th Five-year Plan of Education Science of Shaanxi (Grant No. 2 SGH13382), "Research Project of Shaanxi Preschool Normal University (Grant No. 11KJ059)" and "Teaching Reform Project of Shaanxi Preschool Normal University (Grant No. 13JG014Y)”.

\section{References}

[1] Cai Hongsheng. Reflections on Some Questions Concerning with Mathematics Learning in the Light of the Mathematics History [J]. Curriculum Teaching Material and Method, 2016, 36(12): 66-72.

[2] Jing Li. On Teaching the History of Mathematics in Advanced Algebra Course [J]. Journal of Southwest China Normal University (Natural Science Edition), 2015, 40(6): 162-165.

[3] Zuo Yuanwu. Exploration on permeating mathematics history education into higher mathematics curriculum in higher vocational colleges [J]. Journal of Harbin Vocational \& Technical College, 2015(3): 15-16.

[4] Yuan Qianqian, Qin Chuangliang, Zhang Cong, Zhang Ying. Exploration about integrating the history of mathematics into higher mathematics teaching [J]. Journal of Science of Teachers'College and University, 2017, 37(3): 77-79. 